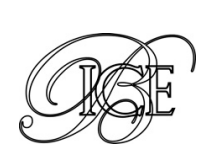

Julián Conthe Yoldi*

\title{
LOS ACUERDOS COMERCIALES EUROPEOS DE NUEVA GENERACIÓN De Seúl a Manila, parando en Hanói
}

En la última década Filipinas se ha consolidado como uno de los pilares de crecimiento del Sudeste Asiático y se encuentra en pleno proceso de modernización y apertura de su economía. En diciembre de 2015, la UE y Filipinas anunciaban la apertura de negociaciones comerciales. Estas seguirán la senda de los acuerdos alcanzados en los últimos años con Corea del Sur, Singapur y Vietnam. El objetivo es concluir un Acuerdo de Libre Comercio (ALC) de nueva generación, completo y ambicioso, que permita apuntalar la presencia europea en la región.

Palabras clave: integración regional, Unión Europea, Asia, ASEAN, comercio internacional, acuerdo de libre comercio.

Clasificación JEL: F15, F20.

\section{Introducción}

Resulta difícil determinar con exactitud cuándo se establecieron los primeros intercambios comerciales entre Europa y Asia. Al igual que ha ocurrido a lo largo de la historia con las distintas civilizaciones, los primeros contactos entre ambos continentes fueron bélicos y solo con el paso del tiempo las guerras fueron dejando sitio a un floreciente comercio entre ambas regiones. Los comerciantes europeos, por entonces en largas caravanas, fueron poco a poco abriéndose paso hacia el Este (Mesopotamia, Asia Central, China), desarrollando rutas comerciales, en general dedicadas al intercambio de productos mediterráneos por manufacturas orientales, como la seda, cuya producción no llegaría a Europa hasta el siglo v. Los intercambios fueron progresivamente diversificándose y las rutas comerciales extendiéndose, pero la difícil orografía y las duras condiciones

* Técnico Comercial y Economista del Estado. Coordinador de los ALC con Filipinas y Singapur, DGTRADE (Comisión Europea).

Versión de marzo de 2016. climáticas de las rutas terrestres pusieron límite a las posibilidades de expansión del comercio entre Europa y Asia.

El auge de la navegación y la exploración marítima transformaron por completo el comercio entre ambas regiones. La llegada de exploradores portugueses y españoles a las costas del océano Índico permitió el desarrollo desde principios del siglo xv de nuevas rutas comerciales entre Europa y Asia más rápidas, económicas y seguras. El Tratado de Zaragoza de 1529 delimitó con exactitud las zonas de influencia de los reinos de España y Portugal en Asia del Sur, pero las rutas comerciales se internacionalizaron con rapidez, terminando con el breve predominio comercial de las potencias peninsulares. Desde entonces, las relaciones comerciales entre ambos continentes se han desarrollado de manera extraordinaria.

Hoy, más del 40 por 100 del comercio europeo tiene por origen o destino el continente asiático. Las grandes potencias económicas del continente son los principales focos de actividad comercial $D$ 


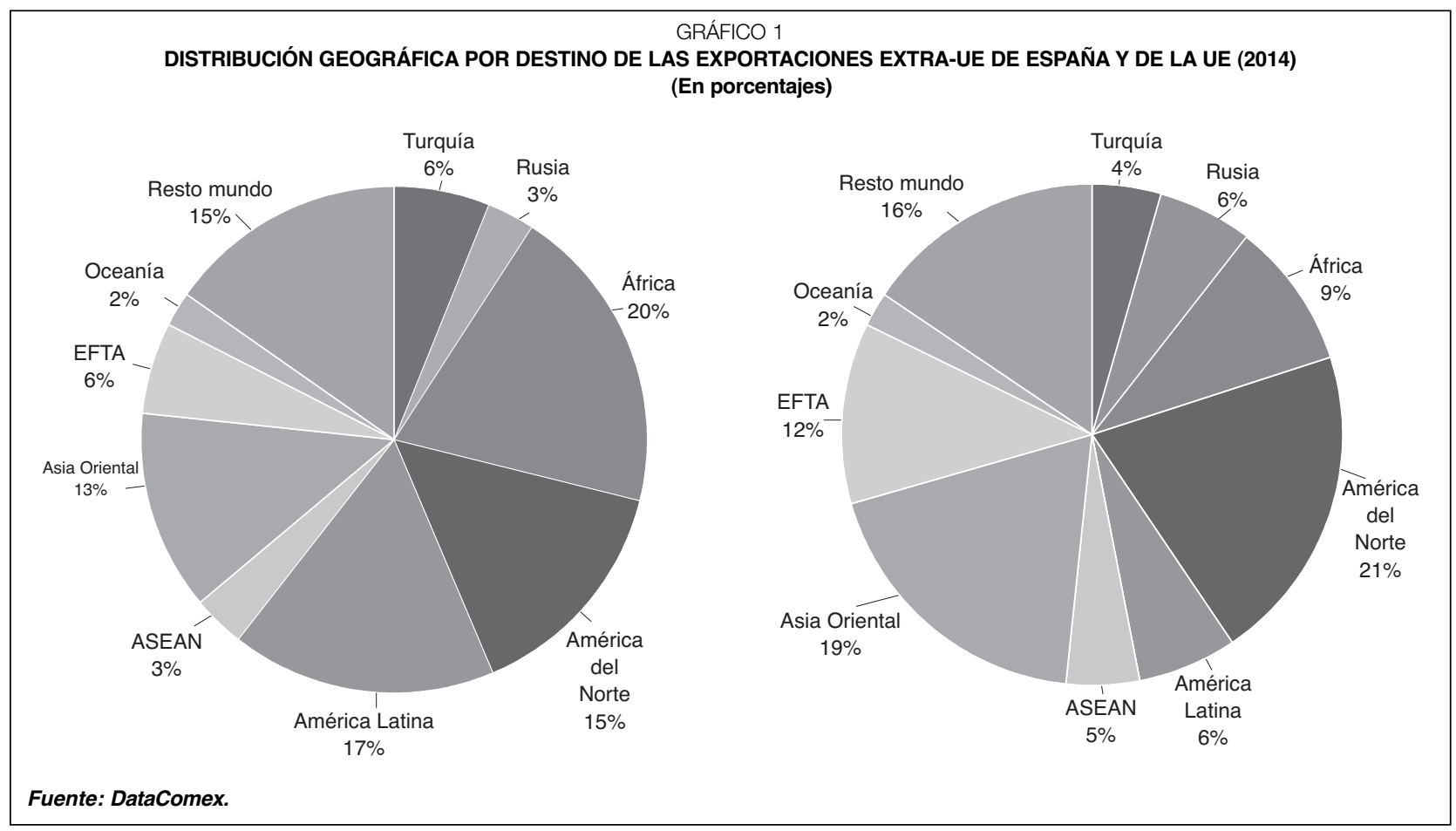

con la UE: China (14,8 por 100 del comercio exterior de la UE), Japón (3,3 por 100) e India (2,2 por 100). Sin embargo, en los últimos años se ha observado un acentuado incremento de los flujos comerciales con las economías emergentes del Sudeste Asiático. En 2015, la UE intercambió bienes con el grupo de países de la Asociación de Naciones del Sudeste Asiático ${ }^{1}$ (ASEAN) por un valor superior a 200 millardos de euros, lo que representa aproximadamente un 6 por 100 del comercio total de la UE con el resto del mundo.

La presencia española en el Sudeste Asiático es por el momento modesta. En 2015, España exportó bienes al conjunto de países de la ASEAN por valor de 3 millardos de euros e importó de los mismos algo más de 6,7 millardos de euros. La participación española en el conjunto de las exportaciones de la UE a los países de la ASEAN fue de 3,6 por 100 en 2015, en torno a un punto por debajo de la media de la participación española en el conjunto de las exportaciones extraregionales de la UE. Esto indicaría que las exportaciones españolas

\footnotetext{
1 La ASEAN está integrada por Brunei, Camboya, Filipinas, Indonesia, Laos, Malasia, Myanmar, Singapur, Tailandia y Vietnam.
}

se encuentran relativamente menos concentradas en el Sudeste Asiático que las de otros países exportadores europeos.

Al observar los datos de manera desagregada, sin embargo, salta a la vista que la cuota española en las exportaciones de la UE a Filipinas se sitúa en torno al 6,6 por 100, lo que indicaría un mayor interés relativo de los exportadores españoles en el mercado filipino que en el resto de mercados de la región. Con todo, las exportaciones españolas a Filipinas siguen siendo relativamente modestas (405 millones de euros en 2015) y tan solo representan un 13,6 por 100 del total de exportaciones españolas al Sudeste Asiático que, como las del resto de Estados miembros de la UE, siguen estando altamente concentradas en Singapur.

\section{Asia en el foco de la agenda comercial de la UE: desembarcando en Corea del Sur}

La Comunicación «Una Europa global: competir en el mundo « presentada por la Comisión Europea en 2006 supuso un punto de inflexión en la $\triangle$ 


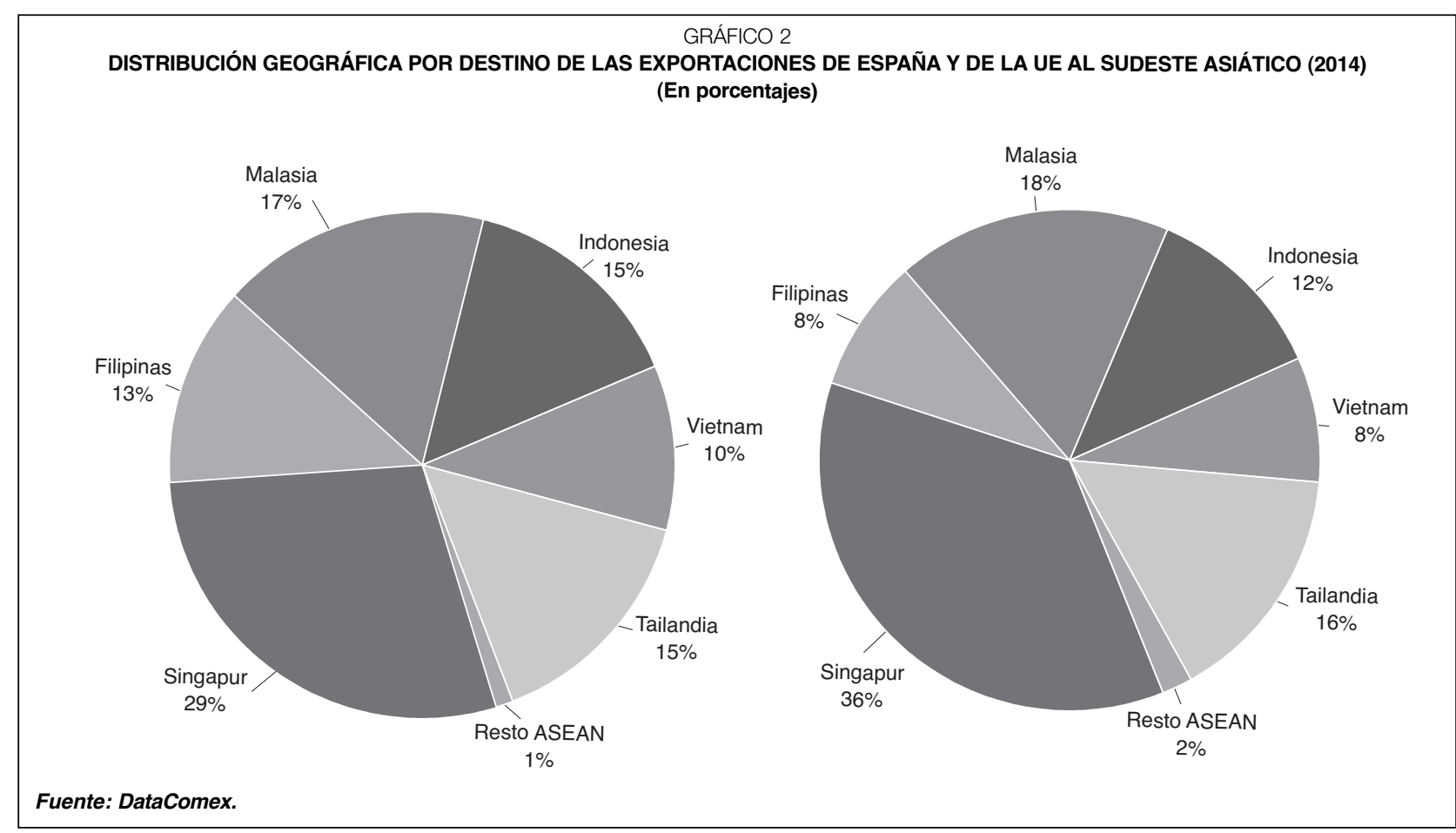

política comercial europea. En ella, la Comisión Europea reconocía por primera vez con claridad la importancia de avanzar en una agenda comercial bilateral que sirviese de complemento de los esfuerzos multilaterales llevados a cabo en el marco de la Ronda Doha de la Organización Mundial de Comercio (OMC). La Comunicación también perfilaba una agenda de negociación centrada en economías con fuerte potencial de crecimiento, identificando entre las prioridades a Corea del Sur, India y los países de la ASEAN.

El segundo elemento clave de la estrategia de la Comisión Europea fue el compromiso de negociar acuerdos ambiciosos, completos y amplios en su contenido, que abarcasen tanto el comercio tradicional de bienes como el comercio de servicios, la inversión, las barreras no arancelarias y los aspectos comerciales de los derechos de propiedad intelectual, la contratación pública, la competencia y el desarrollo sostenible.

En 2007, con el lanzamiento de negociaciones con Corea del Sur, con India y con un subgrupo de países de la $\operatorname{ASEAN}^{2}$, la Comisión Europea

2 Las negociaciones fueron inicialmente lanzadas con los 7 países de la ASEAN no pertenecientes al grupo de países menos adelantados (Camboya, Laos y Myanmar), beneficiarios del esquema de preferencias EBA (todo menos armas, por sus siglas en inglés). comenzó a poner en práctica la estrategia formulada. El primer gran logro de la misma llegó con la conclusión en 2009 de las negociaciones para un Acuerdo de Libre Comercio (ALC) con Corea del Sur. El acuerdo entró en vigor de manera provisional en julio de 2011 y tras ser ratificado por el Parlamento Europeo y los parlamentos de los 28 Estados miembros de la UE fue concluido a finales de 2015.

El acuerdo con Corea del Sur supuso un antes y un después en la política comercial europea. Por un lado, se trataba del primer ALC que la Unión firmaba con una nación asiática y también del primero que la UE alcanzaba con una economía de un nivel de desarrollo comparable al de la Unión. Pero más importante que esto, el ALC marcó un hito por ser el primero de una nueva generación de ALC, más completo y amplio de los que posteriormente se han concluido con Canadá, Singapur y Vietnam.

Desde su entrada en vigor en 2011, la implementación del acuerdo ha sido objeto de seguimiento por parte de la Comisión Europea, que ha publicado un informe anual al respecto. Los sucesivos informes muestran una evolución de los flujos de $\triangleright$ 
GRÁFICO 3

EVOLUCIÓN DE LAS EXPORTACIONES E IMPORTACIONES ESPAÑOLAS CON COREA DEL SUR Y CON TERCEROS PAÍSES NO UE

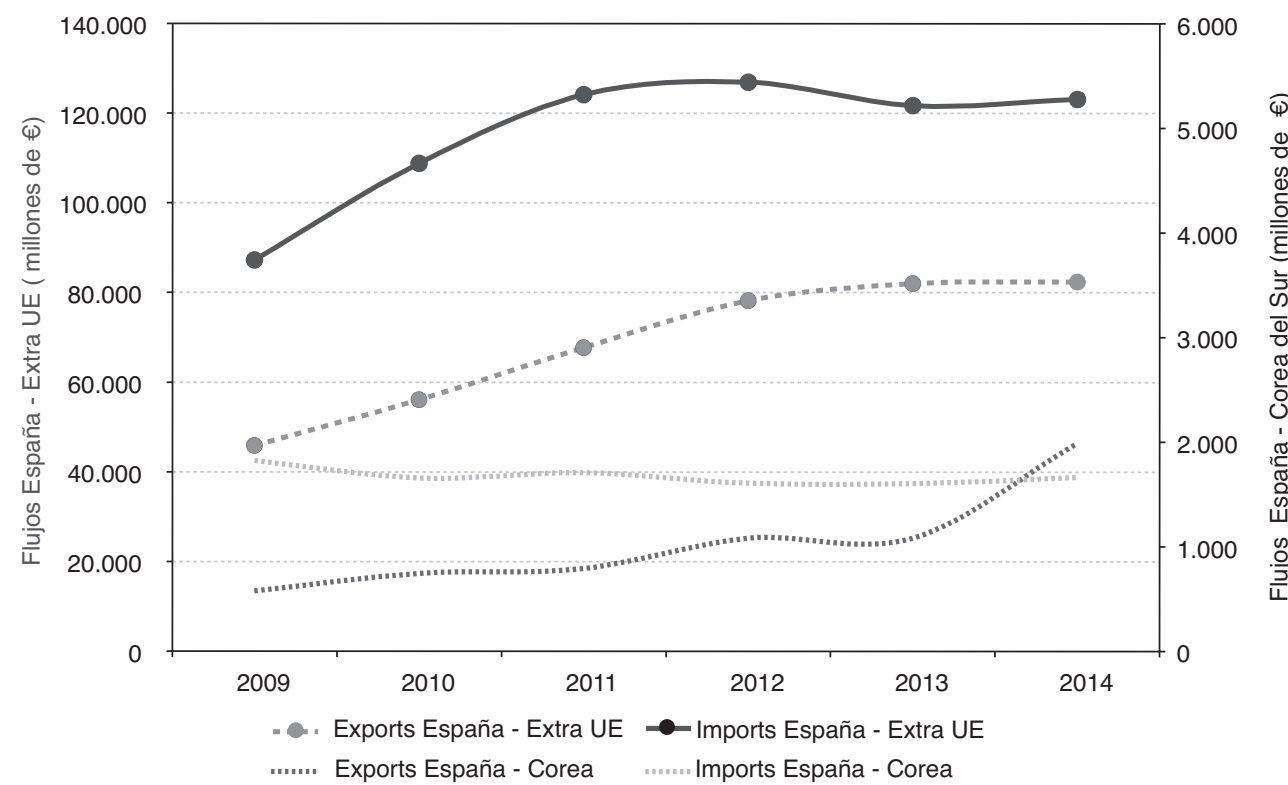

Fuente: DataComex

comercio e inversión de la UE con Corea del Sur muy positiva desde 2011. Las exportaciones de la UE a Corea del Sur han crecido entre 8-15 por 100 anual durante los primeros cuatro años de aplicación del acuerdo, lo que para el conjunto del periodo supone un crecimiento de más de 10 puntos superior al de las exportaciones europeas al resto del mundo. Esta evolución de las exportaciones ha permitido a la UE incrementar su cuota de mercado en el conjunto de las importaciones coreanas de un 9 a un 13 por 100 .

Las exportaciones coreanas a la UE también han crecido en este periodo, si bien de manera más moderada, por la debilidad de la demanda en la UE, lo que ha convertido el amplio déficit comercial, que la UE tenía con Corea del Sur en 2011, en un superávit comercial por valor de más de 5 millardos de euros en 2015. Este reequilibrio de las relaciones comerciales entre ambos socios desde la entrada en vigor del acuerdo ha tenido su reflejo más claro en el comercio de vehículos de motor. Las ventas de vehículos europeos a Corea del Sur se han triplicado en cuatro años, hasta superar las 200.000 unidades anuales y un valor de exportación de 4,7 millardos de euros, lo que ha permitido a la UE cerrar el importante déficit comercial que tenía hasta recientemente con Corea del Sur en el sector.
En el caso concreto de España, se ha podido observar cómo las exportaciones a Corea del Sur se han incrementado en un 168 por 100 desde la entrada en vigor del acuerdo (mientras las importaciones han permanecido razonablemente estables), lo que contrasta con un incremento del 47 por 100 de las exportaciones de España fuera de la UE en el mismo periodo.

El comercio de servicios entre la UE y Corea del Sur también ha crecido de manera significativa. Las exportaciones europeas de servicios a Corea del Sur han pasado de valer 7,4 millardos de euros en 2010 a 11,9 millardos de euros en 2014, lo que refleja un incremento del 61 por 100, muy superior al incremento del 34 por 100 observado en las exportaciones europeas de servicios al resto del mundo en el mismo periodo. El stock de inversión directa extranjera europea en Corea del Sur también ha crecido en este periodo, si bien de manera más moderada, pasando de 37,5 millardos de euros en 2010 a 43,7 millardos de euros en 2014.

\section{Los acuerdos comerciales de nueva generación con Asia}

El acuerdo con Corea del Sur fue el primero de una nueva generación de ALC más completos y $\triangleright$ 
amplios, como los que le han seguido con Singapur y Vietnam; este últmo incluía un rápido desmantelamiento recíproco de aranceles sobre la práctica totalidad de líneas arancelarias. En todos estos acuerdos la supresión arancelaria se produce, en su mayor parte, a la entrada en vigor del acuerdo, siendo el resto de aranceles objeto de una eliminación progresiva en un plazo que varía en cada acuerdo. En el caso de Corea del Sur, la fecha límite de eliminación arancelaria negociada fue de cinco años, mientras en el acuerdo con Vietnam, por su menor grado de desarrollo, este periodo transitorio es de 10 años $^{3}$.

Sin embargo, los acuerdos de nueva generación buscan ir mas allá y complementan el desmantelamiento arancelario con disposiciones adicionales para garantizar un mejor acceso recíproco a los mercados. Se pone énfasis, por ejemplo, en la supresión de barreras no arancelarias al comercio, en especial en sectores donde estas suelen ser más habituales (automóvil, electrónica, tecnologías verdes y productos farmacéuticos). Los anexos sectoriales incluidos en los acuerdos buscan que aquellos reglamentos técnicos y procedimientos de evaluación de conformidad, que persiguen objetivos similares en cada país, no supongan una carga doble para los exportadores respectivos. En este sentido, se apuesta por el recurso generalizado a normas internacionales para reducir la divergencia de requisitos en materia de certificación de productos, si bien también se encuentran soluciones prácticas para facilitar los intercambios en aquellas áreas donde los reglamentos técnicos nacionales no se encuentren alineados con los internacionales.

Por ejemplo, los ALC concluidos con Corea del Sur, Singapur y Vietnam reconocen las normas internacionales de CEPE/ONU como equivalentes a las normas nacionales de estos países en materia

\footnotetext{
${ }^{3}$ El caso de Singapur es particular, pues más de una década antes del inicio de las negociaciones entre la UE y Singapur, el país asiático decidió de manera unilateral suprimir los aranceles no preferenciales sobre todas las líneas arancelarias, a excepción de la cerveza. En el acuerdo con la UE, Singapur se comprometió a consolidar esta eliminación arancelaria y a extenderla a las líneas arancelarias de la cerveza desde la entrada en vigor del acuerdo.
}

de seguridad, lo que permite que un vehículo producido en la UE y con un certificado de homologación CEPE/ONU sea aceptado como conforme con las normas nacionales en vigor en estos países. Esto supone un ahorro de costes considerable para los productores de coches europeos (en líneas específicas de producción para cada mercado, en costosos ensayos adicionales de resistencia a colisiones, etcétera) que no tendrán que modificar sustancialmente los vehículos fabricados con arreglo a las especificaciones de la UE para poder venderlos en los mercados de los países socios.

\section{ESTRUCTURA TÍPICA DE LOS ACUERDOS DE NUEVA GENERACIÓN DE LA UE}

1. Objetivos y definiciones generales

2. Trato nacional y acceso de las mercancías al mercado (incluyendo anexos de barreras no arancelarias al comercio)

3. Soluciones comerciales

4. Barreras técnicas al comercio

5. Medidas sanitarias y fitosanitarias

6. Aduanas y facilitación del comercio

7. Comercio de servicios, inversión (incluyendo protección de la inversión) y comercio electrónico

8. Contratación pública

9. Propiedad intelectual

10. Competencia

11. Comercio y desarrollo sostenible

12. Solución de diferencias y mecanismo de mediación

13. Transparencia

14. Disposiciones institucionales, generales y finales

También en relación con los productos de origen animal, vegetal y otros productos alimenticios, los acuerdos de nueva generación establecen mecanismos para impulsar el comercio, manteniendo un elevado nivel de protección de la salud y seguridad humana, animal y vegetal. Se desarrollan, por ejemplo, procedimientos para la homologación de establecimientos cárnicos para la exportación, mediante los cuales las autoridades del país importador mantienen una lista de productores europeos autorizados para exportar a sus mercados sin necesidad de haber inspeccionado de antemano cada establecimiento exportador (que se encontrará sujeto a la normativa europea en materia de $D$ 
inspección sanitaria). Se trata de un sistema basado en la confianza mutua en los respectivos sistemas de certificación e inspección que permite agilizar el comercio en productos de origen animal y vegetal entre las partes.

Los mencionados ALC concluidos con Corea del Sur, Singapur y Vietnam ofrecen también un acceso preferencial a sus mercados respectivos a los proveedores de servicios e inversores europeos en sectores como las telecomunicaciones, las finanzas, los servicios profesionales, el transporte, el turismo y los servicios medioambientales. En todos estos acuerdos, ambas partes han ofrecido compromisos de acceso a mercado que, por su amplitud y cobertura sectorial, son los más ambiciosos ofrecidos hasta la fecha por cada socio en sus respectivos acuerdos comerciales. Los capítulos de servicios e inversión incluyen además sólidas disciplinas en materia de no discriminación y transparencia. Así, por ejemplo, en relación con los servicios de telecomunicación, los acuerdos incluyen disposiciones sobre interconexión, desagregación, coubicación, portabilidad de números y obligaciones de servicio universal, mientras en relación con el sector postal se incluyen disciplinas respecto a la independencia del regulador y la prohibición de prácticas anticompetitivas.

Como novedad, los acuerdos concluidos con Singapur y Vietnam incorporan un apartado de protección de las inversiones, un área que con el Tratado de Lisboa ha pasado al ámbito competencial de la Unión. Al entrar en vigor los nuevos acuerdos, estos pasarán a sustituir los acuerdos de promoción y protección recíproca de inversiones (APPRI) que algunos Estados miembros tienen actualmente en vigor con Singapur y Vietnam (en el caso de España solo con este último). Cabe destacar que los capítulos de protección de inversión incluidos en estos acuerdos de nueva generación incorporan importantes innovaciones respecto a los APPRI de corte antiguo, entre ellas la reafirmación del derecho a regular, una definición más clara de trato justo y equitativo, estrictas disposiciones sobre lo que constituye una expropiación indirecta y un mecanismo mejorado para la resolución de disputas entre inversor y Estado.

Otro pilar importante de los ALC de nueva generación es el referido a la contratación pública, que en las economías desarrolladas puede representar un valor de entre un 10-20 por 100 del PIB e incluso algo más en economías emergentes. $A$ través de los acuerdos se busca garantizar que las empresas europeas no sean discriminadas respecto a las nacionales en aquellas convocatorias de contratos públicos abiertos a la participación de las primeras. Por un lado, los acuerdos incluyen disposiciones para favorecer la transparencia respecto a la publicación de las convocatorias y los procedimientos de contratación (adjudicación, recurso, etcétera). Estas disciplinas están en línea con el Acuerdo Plurilateral sobre Contratación Pública (ACP) de la $\mathrm{OMC}$, pero en algunos aspectos van más allá. Por otra parte, los ALC incluyen listados detallando las entidades contratantes públicas (centrales, subcentrales $u$ otras) y los umbrales de contratación por encima de los cuales los contratos de bienes, servicios y la concesión de obras públicas quedan abiertos a la participación de empresas del país socio.

Los ALC de nueva generación también contienen un capítulo en relación con los derechos de propiedad intelectual, basado en el Acuerdo ADPIC (TRIPS en sus siglas en inglés) de la OMC, pero que va más allá de las disposiciones del mismo en ciertos aspectos. Por ejemplo, los ALC extienden el nivel de protección que el ADPIC ofrece a las indicaciones geográficas del vino y las bebidas espirituosas también a los productos agrícolas y alimenticios (por ejemplo, jamón de Guijuelo, aceite de oliva de la Sierra de Cádiz, salchichón de Vic, queso manchego, cítricos valencianos y turrón de Alicante). Los acuerdos también ponen énfasis en la puesta en marcha de medidas que garanticen una acción eficaz contra las infracciones en relación con los derechos de propiedad intelectual.

Por último, los ALC concluidos con Corea del Sur, Singapur y Vietnam contienen capítulos sobre competencia y sobre desarrollo sostenible. En el primero se aborda la necesidad de una aplicación $\triangle$ 
no discriminatoria de la ley de competencia de cada una de las partes y se establecen disciplinas en relación con la concesión de subvenciones que puedan distorsionar los intercambios comerciales entre los socios. En el capítulo de comercio y desarrollo sostenible las partes se comprometen a un efectivo cumplimiento de su legislación laboral y medioambiental, así como a la aplicación de las obligaciones derivadas de su adhesión a la Organización Internacional del Trabajo (OIT) y a los acuerdos medioambientales multilaterales de los que son parte. Finalmente, con el fin de incrementar la participación ciudadana en la implementación de los acuerdos, y particularmente del capítulo de desarrollo sostenible, se crean mecanismos de diálogo con la sociedad civil que procuran ser lo más abiertos e inclusivos posibles.

\section{Aterrizando en el Sudeste Asiático y el efecto Vietnam}

En 2007, en paralelo con el lanzamiento de negociaciones con Corea del Sur, la Comisión Europea anunció el lanzamiento de negociaciones con los países de la ASEAN. Mientras el objetivo era alcanzar un acuerdo con el conjunto de países de la ASEAN, el mandato que el Consejo otorgó a la Comisión concedía cierta flexibilidad respecto al formato de negociación. Las negociaciones debían iniciarse con el conjunto de los 7 países de la ASEAN no pertenecientes al grupo de países menos adelantados (Camboya, Laos y Myanmar), si bien estaba prevista la posibilidad de extender éstas al conjunto de la ASEAN o, en caso de que una negociación región a región resultase infructuosa, de optar por un formato de negociación distinto (bilateral o plurilateral).

Entre 2007 y 2009 se celebraron 7 rondas de negociación entre la UE y ASEAN. Con el paso de las mismas se fue haciendo cada vez más evidente que existían entre los Estados miembros de la ASEAN diferencias importantes de objetivos e intereses que, sumadas a la falta de mecanismos internos de coordinación y arbitraje entre los mismos, hacía imposible avanzar de manera sustantiva hacia un acuerdo. El estancamiento de las negociaciones a nivel regional acabó precipitando la decisión de pausar las negociaciones y dar paso a la negociación bilateral de acuerdos entre la UE y aquellos Estados miembros de la ASEAN con capacidad y voluntad de negociar un acuerdo comercial ambicioso y de amplio alcance.

Los preceptivos ejercicios de alcance/delimitación (scoping exercise) entre la UE y aquellos Estados miembros de la ASEAN que mostraron voluntad por entablar negociaciones bilaterales permi tieron evaluar el grado de entendimiento mutuo entre ambas partes en relación con los objetivos y el alcance de un futuro acuerdo. En base a este entendimiento, la UE lanzó negociaciones con Singapur y Malasia en 2010, Vietnam en 2012, Tailandia en 2013 y finalmente con Filipinas en 2015. Estas negociaciones bilaterales fueron concebidas desde su origen como peldaños hacia un acuerdo región a región. En este sentido, pese a que cada negociación ha seguido su curso, la Comisión Europea ha realizado un especial esfuerzo por asegurar la máxima coherencia posible entre las negociaciones bilaterales con los distintos Estados miembros de la ASEAN.

La estrategia de negociaciones bilaterales puesta en marcha en 2009 ha comenzado a dar frutos con la conclusión de las negociaciones con Singapur en 2014 y Vietnam en 2015. Ambos acuerdos siguen la senda del anteriormente concluido con Corea del Sur y son de ambición y alcance comparables. La reciente Comunicación «Comercio para todos» de la Comisión Europea reafirma la estrategia negociadora de la UE con el Sudeste Asiático y reconoce el enorme valor de los acuerdos concluidos con Singapur y Vietnam como claras referencias para las negociaciones con Malasia y Tailandia (que se encuentran en este momento en suspenso) y con Filipinas.

En este contexto, resulta especialmente remarcable la apuesta decidida que las autoridades vietnamitas han hecho en los últimos años por la $D$ 
apertura económica del país. Por un lado, el acuerdo concluido entre la UE y Vietnam en 2015 es de una ambición muy similar, e incluso superior en ciertos aspectos, al anteriormente concluido entre la UE y Singapur. Por otro lado, Vietnam ha participado junto con otros 11 socios $^{4}$ en la conclusión del Acuerdo Transpacífico de Cooperación Económica (TPP por sus siglas en inglés), el primer acuerdo plurilateral entre países de distintos continentes, que es amplio y completo -como los acuerdos de nueva generación de la UE- y contiene disposiciones en materia de facilitación de comercio, barreras no arancelarias, competencia, empresas públicas, contratación pública, etcétera.

La determinación con la que Vietnam ha optado por una estrategia de desarrollo basada en la apertura económica no ha pasado inadvertida para sus vecinos del Sudeste Asiático. Por un lado, porque los acuerdos con la UE y con EEUU (en el marco del TPP) sitúan a Vietnam en una posición privilegiada de cara al futuro en sus relaciones con dos de las principales potencias económicas y comerciales globales. Las exportaciones vietnamitas, que en muchos sectores compiten con las de sus socios de la ASEAN, pasarán pronto a disfrutar de un acceso preferencial a los mercados europeo y americano y podrían ir rápidamente incrementando su cuota de mercado en los mismos, a expensas de las de países como Tailandia, Filipinas e Indonesia. Por otro lado, Vietnam asume con estos acuerdos una serie de compromisos que hasta ahora países de un grado de desarrollo similar al de Vietnam no habían mostrado voluntad de asumir $^{5}$. Así, tras el anuncio de la conclusión del ALC UE-Vietnam y del TPP en la segunda mitad de 2015, varios Gobiernos de la región se apresuraron a expresar su interés por unirse al TPP cuando este se abra a nuevos miembros y por negociar o retomar las negociaciones de ALC bilaterales con la UE.

\footnotetext{
${ }^{4}$ Australia, Brunei, Canadá, Chile, Estados Unidos, Japón, Malasia, México, Nueva Zelanda, Perú y Singapur.

5 Entre los países miembros del TPP, Vietnam es con diferencia el país de menor desarrollo económico, con una renta per cápita inferior a la mitad de la de Perú y cuatro veces menor que la de México y Malasia.
}

\section{Filipinas busca su sitio}

Filipinas se encuentra hoy atravesando un periodo de relativa estabilidad política y económica. En la última década la economía filipina ha duplicado su tamaño y se ha afianzado como uno de los pilares de crecimiento del Sudeste Asiático. El fuerte crecimiento económico de los últimos años ha sido, además, aprovechado para llevar a cabo una serie de importantes reformas estructurales para la modernización de la economía y una progresiva apertura de la misma al exterior.

Las reformas internas han venido acompañadas por un progresivo acercamiento del país a sus principales socios comerciales. Por un lado, en 2015, Filipinas y sus socios del Sudeste Asiático proclamaban el establecimiento de la Comunidad Económica de la ASEAN. Además, como miembro de la ASEAN, entre 2008 y 2015, Filipinas ha participado de los cinco acuerdos comerciales que ASEAN ha concluido con China, India, Japón, Corea del Sur y Australia y Nueva Zelanda. Por último, en el plano bilateral, Filipinas mantiene un ALC con Japón (que entró en vigor en 2008) y se encuentra concluyendo la negociación de otro con los países de la Asociación Europea de Libre Comercio (EFTA por sus siglas en inglés).

En este contexto,en 2015 las autoridades filipinas expresaron su voluntad de negociar con la UE un ALC de ambición y alcance equivalentes a los que la UE ha concluido con Singapur y Vietnam. Llama la atención que el lanzamiento de negociaciones entre la UE y Filipinas, en diciembre de 2015, se produjese exactamente un año después de que Filipinas se incorporase al Sistema de Preferencias Generalizadas Plus (SPG+) que otorga un acceso privilegiado a sus exportaciones al mercado europeo. Filipinas parece haber tomado consciencia de que las preferencias unilaterales ofrecidas por la UE a través del SPG + tienen fecha de caducidad (al ritmo de crecimiento económico actual, el país podría perder la condición de economía de renta media-baja que le da acceso al SPG+ en 6 o 7 años) y que la ventaja competitiva que $D$ 
éstas le ofrecen solo puede esperar mantenerla a través de la negociación de un acuerdo bilateral con la UE.

Pese al proceso de reformas, Filipinas sigue siendo una economía relativamente cerrada. Esto tiene su reflejo en la cuota relativamente modesta del país en el comercio de bienes y servicios de la UE con ASEAN (6,4 por 100) y en el stock de inversión directa de la UE en ASEAN (3,6 por 100), muy inferiores al peso del país en la región en términos de producto y población: 11,5 por 100 y 16 por 100 respectivamente. El acuerdo comercial que la UE negocia en la actualidad con Filipinas proporcionará un marco legal estable y duradero para el desarrollo equilibrado de las relaciones comerciales y de inversión entre ambos socios.

Tanto por su tamaño como por su potencial de crecimiento, el mercado filipino es un mercado de un enorme atractivo. Con más de 100 millones de habitantes, Filipinas es el segundo país más poblado del Sudeste Asiático. Su población es además la segunda más joven de la región (con una edad media de 23 años) y su clase media está creciendo con rapidez y desarrollando un gusto cada vez mayor por los productos occidentales. Así, Filipinas va constituyéndose como un mercado de gran interés para los exportadores europeos en los distintos sectores. En 2014, Filipinas fue el tercer destino del Sudeste Asiático para las exportaciones europeas de equipos de transporte, el segundo importador de la región de bebidas alcohólicas de origen europeo y el principal mercado de la ASEAN para los productos agrícolas europeos. Estos sectores, de gran interés para el sector exportador español, se encuentran sin embargo relativamente protegidos en Filipinas por elevados aranceles que la negociación del ALC entre la UE y Filipinas debería permitir eliminar.

También en el sector servicios, los intercambios con Filipinas presentan un enorme potencial de expansión. Por un lado, los compromisos adoptados por el país en el Acuerdo General sobre Comercio de Servicios (GATS por sus siglas en inglés) son relativamente pobres y los sectores de mayor interés económico se encuentran relativamente cerrados a los proveedores de servicios e inversores extranjeros. Por otro lado, Filipinas es el segundo país de ASEAN (solo por detrás de Singapur) con mayor participación del sector servicios en la economía y dispone de una mano de obra altamente cualificada y angloparlante y de unos costes laborales moderados, que le otorgan una importante ventaja comparativa en el sector respecto a economías vecinas. Así, por ejemplo, en los últimos años Filipinas se ha convertido en líder mundial en el sector de la externalización de procesos de negocio (business process outsourcing). Otros sectores, como las telecomunicaciones, la energía, el turismo o el transporte se encuentran en plena transformación y un ALC permitiría a las empresas europeas participar de la misma.

También en el ámbito de la contratación pública, la firma de un acuerdo comercial con Filipinas permitiría a las empresas europeas, muchas de ellas españolas, un mejor acceso a un mercado de gran interés económico. El importante déficit de infraestructuras del país ha sido durante años el principal cuello de botella del desarrollo económico de Filipinas, y el Gobierno filipino esá llevando a cabo un ambicioso plan de desarrollo de infraestructuras de transporte, de telecomunicación y de energía valorado en 70 millardos de dólares. Una vez concluido, el ALC entre la UE y Filipinas debería permitir a las empresas europeas participar en los concursos públicos en pie de igualdad con las empresas filipinas.

\section{Conclusión}

Los datos muestran que la concentración comparativamente alta de las exportaciones españolas en regiones como América Latina y el norte de África tienen su contrapunto en una menor presencia española en el Sudeste Asiático. Sin embargo, resulta interesante que Filipinas tenga una importancia relativamente mayor para España que para el conjunto de la UE como destino de exportación, en comparación con el resto de mercados del Sudeste Asiático. 
El espectacular crecimiento de las exportaciones españolas a Corea del Sur desde la entrada en vigor del ALC en 2011 muestra el potencial de incremento de exportaciones que estos acuerdos ofrecen. El ALC que la Comisión Europea acaba de empezar a negociar con las autoridades filipinas constituirá el futuro marco de las relaciones comerciales entre ambos socios y favorecerá una apertura bilateral de ambas economías que generará nuevas e interesantes oportunidades de negocio.
Aún pasarán varios años antes de que ambas partes concluyan un acuerdo y éste pueda entrar en vigor. Este tiempo debería ser aprovechado por los exportadores e inversores españoles para acercarse al mercado filipino y empezar a conocerlo, de manera que una vez el acuerdo entre en vigor, puedan desembarcar con celeridad en el país. Entretanto irán entrando en vigor los acuerdos que la UE ha negociado con Singapur y Vietnam, y que deberían posibilitar una mayor presencia española en estos mercados y en el conjunto del Sudeste Asiático. 


\section{SUSCRIPCIÓN ANUAL}

\begin{tabular}{|c|c|c|c|}
\hline \multicolumn{2}{|c|}{ BOLETÍN ECONÓMICO DE INFORMACIÓN COMERCIAL ESPAÑOLA (12 NÚMEROS) } \\
\hline SUSCRIPCIÓN & $\begin{array}{c}\text { ESPAÑA } \\
1 \text { año }\end{array}$ & $\begin{array}{c}\text { UNIÓN EUROPEA } \\
1 \text { año }\end{array}$ & $\begin{array}{c}\text { RESTO DEL } \\
\text { MUNDO } \\
1 \text { año }\end{array}$ \\
\hline $\begin{array}{c}\text { Gastos de envío } \\
\text { España }\end{array}$ & $5,76 €$ & $24,36 €$ & $30,00 €$ \\
\hline $\begin{array}{c}\text { Más 4\% de IVA. } \\
\text { Excepto Canarias, Ceuta y Melilla }\end{array}$ & $2,83 €$ & $85,00 €$ & $85,00 €$ \\
\hline TOTAL & $73,59 €$ & $109,36 €$ & $115,00 €$ \\
\hline & & & \\
\hline
\end{tabular}

\section{EJEMPLARES SUELTOS}

\section{BOLETÍN ECONÓMICO DE INFORMACIÓN COMERCIAL ESPAÑOLA}

\begin{tabular}{|c|c|c|c|}
\hline & $\begin{array}{l}\text { ESPAÑA } \\
1 \text { ejemplar }\end{array}$ & $\begin{array}{c}\text { UNIÓN EUROPEA } \\
1 \text { ejemplar }\end{array}$ & $\begin{array}{l}\text { RESTO DEL } \\
\text { MUNDO } \\
1 \text { ejemplar }\end{array}$ \\
\hline NÚMERO SUELTO & $7,00 €$ & $9,00 €$ & $9,00 €$ \\
\hline $\begin{array}{l}\text { Gastos de envío } \\
\text { España }\end{array}$ & $0,48 €$ & $2,03 €$ & $2,50 €$ \\
\hline $\begin{array}{l}\text { Más } 4 \% \text { de IVA. } \\
\text { Excepto Canarias, Ceuta y Melilla }\end{array}$ & $0,30 €$ & & \\
\hline TOTAL & $7,78 €$ & $11,03 €$ & $11,50 €$ \\
\hline \multicolumn{4}{|l|}{ BOLETÍN ECONÓMICO } \\
\hline & $\begin{array}{l}\text { ESPAÑA } \\
1 \text { ejemplar }\end{array}$ & $\begin{array}{c}\text { UNIÓN EUROPEA } \\
1 \text { ejemplar }\end{array}$ & $\begin{array}{l}\text { RESTO DEL } \\
\text { MUNDO } \\
1 \text { ejemplar }\end{array}$ \\
\hline $\begin{array}{l}\text { NÚMERO SUELTO } \\
\text { EXTRAORDINARIO }\end{array}$ & $12,00 €$ & $15,00 €$ & $15,00 €$ \\
\hline Gastos de envío España & $0,48 €$ & $2,03 €$ & $2,50 €$ \\
\hline $\begin{array}{l}\text { Más } 4 \% \text { de IVA. } \\
\text { Excepto Canarias, Ceuta y Melilla }\end{array}$ & $0,50 €$ & & \\
\hline TOTAL & $12,98 €$ & $17,03 €$ & $17,50 €$ \\
\hline & & & \\
\hline
\end{tabular}

\section{DATOS}

Nombre y apellidos

Empresa

Domicilio

D.P.

N.I.F.

Teléf.

Email.
Transferencia a la cuenta de ingresos por venta de publicaciones del Ministerio de Economía y Competitividad.

IBERCAJA. Calle Alcalá 29. 28014 MADRID (ESPAÑA) CÓDIGO CUENTA CLIENTE: 2085-9252-07-0330598330 CÓDIGO BIC DE IBERCAJA: CAZRES2Z

IBAN: ES47 2085-9252-07-0330598330

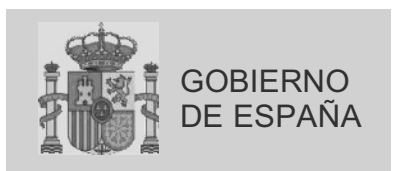

\section{MINISTERIO}

DE ECONOMÍA Y

COMPETITIVIDAD
SUBSECRETARÍA

SECRETARÍA GENERAL TÉCNICA

SUBDIRECCIÓN GENERAL

ESTUDIOS, INFORMACIÓN Y PUBLICACIONES

Suscripciones y ventas por correspondencia:

Paseo de la Castellana, 162 9 Planta 28046 Madrid. Teléfono 91603 79 97/93

Suscripciones a través de la página web del Ministerio de Economía y Competitividad

distribucionpublicaciones@mineco.es 